\title{
BMJ Open Unexplained mortality during the US COVID-19 pandemic: retrospective analysis of death certificate data and critical assessment of excess death calculations
}

\author{
Kathleen A Fairman (D) , ${ }^{1,2}$ Kellie J Goodlet (D) , ${ }^{1}$ James D Rucker, ${ }^{2}$ \\ Roy S Zawadzki ${ }^{3}$
}

To cite: Fairman KA, Goodlet KJ, Rucker JD, et al. Unexplained mortality during the US COVID-19 pandemic: retrospective analysis of death certificate data and critical assessment of excess death calculations. BMJ Open 2021;11:e050361. doi:10.1136/ bmjopen-2021-050361

- Prepublication history and additional supplemental material for this paper are available online. To view these files, please visit the journal online (http://dx.doi.org/10.1136/ bmjopen-2021-050361).

Received 18 February 2021 Accepted 29 October 2021

D) Check for updates

C Author(s) (or their employer(s)) 2021. Re-use permitted under CC BY-NC. No commercial re-use. See rights and permissions. Published by BMJ.

'Department of Pharmacy Practice, Midwestern University College of Pharmacy, Glendale, Arizona, USA

${ }^{2}$ Kathleen Fairman LTD, Phoenix, Arizona, USA

${ }^{3}$ Department of Statistics,

Donald Bren School of

Information and Computer

Sciences, University of

California, Irvine, California, USA

Correspondence to

Dr Kathleen A Fairman;

kfairm@midwestern.edu

\section{ABSTRACT}

Objectives Cause-of-death discrepancies are common in respiratory illness-related mortality. A standard epidemiological metric, excess all-cause death, is unaffected by these discrepancies but provides no actionable policy information when increased all-cause mortality is unexplained by reported specific causes. To assess the contribution of unexplained mortality to the excess death metric, we parsed excess deaths in the COVID-19 pandemic into changes in explained versus unexplained (unreported or unspecified) causes.

Design Retrospective repeated cross-sectional analysis, US death certificate data for six influenza seasons beginning October 2014, comparing population-adjusted historical benchmarks from the previous two, three and five seasons with 2019-2020.

Setting 48 of 50 states with complete data.

Participants 16.3 million deaths in 312 weeks, reported in categories-all causes, top eight natural causes and respiratory causes including COVID-19.

Outcome measures Change in population-adjusted counts of deaths from seasonal benchmarks to 20192020, from all causes (ie, total excess deaths) and from explained versus unexplained causes, reported for the season overall and for time periods defined a priori: pandemic awareness (19 January through 28 March); initial pandemic peak (29 March through 30 May) and pandemic post-peak (31 May through 26 September). Results Depending on seasonal benchmark, $287957-$ 306267 excess deaths occurred through September 2020: 179903 (58.7\%-62.5\%) attributed to COVID-19; 44 022-49 $311(15.2 \%-16.1 \%)$ to other reported causes; 64032-77 $054(22.2 \%-25.2 \%)$ unexplained (unspecified or unreported cause). Unexplained deaths constituted $65.2 \%-72.5 \%$ of excess deaths from 19 January to 28 March and 14.1\%-16.1\% from 29 March through 30 May. Conclusions Unexplained mortality contributed substantially to US pandemic period excess deaths. Onset of unexplained mortality in February 2020 coincided with previously reported increases in psychotropic use, suggesting possible psychiatric or injurious causes. Because underlying causes of unexplained deaths may vary by group or region, results suggest excess death

\section{Strengths and limitations of this study}

- This is the first study to assess the degree to which mortality from unreported or unspecified causes contributed to excess deaths in the US COVID-19 pandemic, raising important policy questions about the utility of the excess death metric.

- We used population-adjusted US national data, accounting for deaths in every category reported by the National Center for Health Statistics (NCHS), including top natural causes and respiratory causes including COVID-19.

- Our statistical analysis was descriptive, but our estimates of excess deaths are similar to those previously developed using more sophisticated statistical analyses of the same data files.

- Study results generalise to the USA through 26 September 2020, but not to other countries, as cause-of-death attribution practices vary crossnationally, or to other pandemic periods, including the COVID-19 case surge in late 2020.

- Although we cite evidence suggesting many of the unspecified cause of deaths may have been due to suicide, overdose or underlying psychiatric causes, we were unable to address this question using the available NCHS data files, particularly in population subgroups that may have been especially vulnerable to injurious causes of mortality during the pandemic.

calculations provide limited actionable information, supporting previous calls for improved cause-of-death data to support evidence-based policy.

\section{INTRODUCTION}

Errors in cause-of-death attribution (CODA) are common in infectious respiratory illness, compromising accurate tracking of disease impact and spread. ${ }^{1-3}$ CODA is especially challenging in COVID-19 because of competing causes of mortality, including cancer, lung disease, obesity-related 
conditions and superannuation. ${ }^{4}$ Compounding this problem, key factors contributing to COVID-19 CODA, such as level of training and expertise of mortality coders, whether laboratory testing is or is not required, financial incentives for reporting and public health delivery systems, vary considerably by country. ${ }^{56}$ These variations make cross-national comparisons of COVID19-attributed mortality problematic, threatening the accuracy of the virus mortality statistics needed for public health decision-making. ${ }^{3}$

A standard metric generally understood to account for these discrepancies is 'excess death', defined as mortality from all causes exceeding that expected from historical experience. ${ }^{7}$ Recent investigators have calculated excess deaths to estimate US COVID-19 impact, using death certificate data made available by the US National Center for Health Statistics (NCHS) ${ }^{7-9}$ Most interpretations of excess death calculations reflect an underlying assumption that $100 \%$ of the change in mortality that took place during the pandemic was attributable, indirectly or directly, to COVID-19. ${ }^{7810}$ The calculation has the advantages of no reliance on CODA, because it considers only all-cause deaths, and of accounting for deaths due to undetected COVID-19 or to use of scarce health system resources by infected patients. ${ }^{7810}$

Despite these advantages, the utility and interpretation of excess death calculations may be compromised by unexplained deaths. Fully adjudicated, final US mortality files report specific causes or contributing factors, as well as demographic characteristics, for each individual decedent. ${ }^{11}{ }^{12}$ In contrast, files made available by the NCHS beginning in May 2020 to facilitate pandemic mortality analysis, which have been used to calculate excess deaths as an indication of the 'full COVID-19 burden', 8 report only aggregated (summed) weekly death counts, grouped into broad diagnostic categories. ${ }^{13} 14$ These categories, shown in online supplemental appendix 1, represent ranges of International Classification of Diseases, 10th Revision (ICD-10) diagnosis codes. ${ }^{13}{ }^{14}$ For excess deaths unexplained by these causes, the true underlying causes are unknown, despite presumably representing appropriate policy targets. For example, markedly different interventions would be suggested by unexplained deaths due to undetected COVID-19, high-speed automobile accidents on empty highways ${ }^{15}$ or delayed care for lifethreatening conditions when people fear using available emergency department capacity. ${ }^{16}$

Risk factors for potential causes of unexplained death vary cross-nationally. For example, US opioid supplies, opioid mortality, substance use disorder prevalence and suicide rates far exceed those of other high-income nations, ${ }^{17}$ suggesting greater psychological vulnerability to pandemic period disruptions. Yet, neither substance misuse nor mental illness is recorded as a cause of death in the currently available NCHS pandemic period mortality files. ${ }^{13} 14$ Risk factors for COVID-19 mortality, such as obesity, smoking and healthcare-associated infections, also demonstrate considerable cross-national variability. ${ }^{17}$
Quantifying unexplained excess deaths would provide information about the degree to which the utility and interpretation of excess death calculations are potentially compromised by unreported or unspecified causes of mortality. Moreover, assessing the timing of unexplained deaths at various pandemic phases would inform current discussions about societal factors that may contribute to pandemic period morbidity and mortality, such as fear of contagion or economic vulnerability. ${ }^{18-20}$ Accordingly, we used publicly available NCHS mortality data files for the past six influenza seasons to calculate the timing and extent of changes in all-cause deaths that were explained versus unexplained by changes in reported causes.

The primary research question was to what degree unexplained mortality contributed to excess mortality during the pandemic. Because the excess mortality calculation represents change in mortality compared with historical experience, we addressed this research question by assessing the contributions of changes in explained versus unexplained causes of death to change in total, allcause death. A secondary research question, intended to provide exploratory information about possible reasons for unexplained mortality, was when unexplained deaths escalated in 2020. We formulated both research questions, a priori to this project, after noticing large numbers of unexplained deaths in analyses for a different exploratory study on CODA. ${ }^{21}$

\section{METHODS}

\section{Design and data source}

This study was a retrospective, repeated cross-sectional analysis of US mortality files made available by the NCHS beginning in 2020 for pandemic period analysis. The data files for 2020 represent provisional causes of death. ${ }^{13}$ The corresponding data files for 2014-2019 represent final adjudicated causes of death, ${ }^{14}$ reported in the same broad diagnostic categories as the 2020 data to facilitate analysis (online supplemental appendix 1).

The study measures were based on reported underlying cause of death (UCOD), defined as 'the disease or injury which initiated the train of morbid events leading directly to death'. ${ }^{22}$ Only one UCOD is reported on each death certificate. The study files include weekly counts of deaths in total (all-cause) and by UCOD category, grouped by state.

In addition to categories representing the top eight US causes of natural death (heart disease, cancer, chronic lower respiratory disease, cerebrovascular disease, Alzheimer's disease, diabetes, influenza and pneumonia, and kidney disease), which together accounted for $66 \%$ of all US deaths in $2017,{ }^{23}$ the files include four additional categories: miscellaneous respiratory conditions, (eg, nasopharyngitis, sinusitis, pneumothorax); septicaemia; COVID-19 and non-specific cause of deaths. ${ }^{13}{ }^{14}$ Nonspecific causes of deaths, described in ICD-10 nomenclature as 'symptoms, signs, and abnormal clinical and laboratory findings not elsewhere classified' (NEC; ICD-10 
range R00-R99), include 'ill-defined and unknown cause of mortality' (R99), ${ }^{13} 14$ a code commonly used pending forensic investigation of injurious death. ${ }^{24}$ Neither the 2020 provisional data nor the corresponding grouped data for 2014-2019 include reporting categories for specific psychiatric causes, including substance use disorders (ICD-10 codes F00-F99 excluding developmental disorders), or for injurious deaths including intentional self-harm (ICD-10 codes X71-X83) and unintentional overdose (ICD-10 codes T36-T50, excluding codes for underdosing). ${ }^{25}$

\section{Data analyses}

Data from 5 October 2014 through 26 September 2020 were downloaded on 22 January 2021. Analyses were performed using open-source analytical tools. ${ }^{11}$ Specifically, Python coding was used with Pandas, a data organisation tool, ${ }^{26}{ }^{27}$ to group data into six influenza seasons, 52 weeks each. Using the same software tools, data for the 2014-2015 to 2018-2019 seasons were population adjusted to July 2019 using US Census data. ${ }^{11} 28$ As in previous research, Connecticut and North Carolina were excluded because of incomplete reporting. ${ }^{8}$ Data were further grouped a priori into time periods roughly corresponding to US trends in COVID-19 mortality: pandemic awareness (19 January through 28 March); initial pandemic peak (29 March through 30 May) and pandemic post-peak (31 May through 26 September).$^{11} 29$

Analyses were descriptive to facilitate the parsing of excess death (ie, change in all-cause death) into explained and unexplained proportions. The decision was in accordance with the principle of parsimony in data presentation, ${ }^{30}$ as we found that descriptive results were similar to those produced using more sophisticated techniques. ${ }^{89}$ For each week, time period and diagnostic category, we calculated prior season averages for three historical benchmark periods: two seasons (2017-2018 to 2018-2019), three seasons (2016-2017 to 2018-2019) and five seasons (2014-2015 to 2018-2019). Averages were calculated as total death count for the indicated time period, divided by number of years. For example, the two-season average for week 1 was the sum of week 1 deaths reported in 2017-2018 and 2018-2019, divided by 2. Three benchmark time periods were used because it is common to compare current year mortality data with several historical benchmarks, ${ }^{31}$ consistent with the need to report sensitivity analyses of epidemiological data. ${ }^{32}$ Weekly prior season averages and 2019-2020 counts were graphed using Matplotlib. ${ }^{33}$

For each week and time period, excess deaths were defined a priori as increases in all-cause deaths over the population-adjusted prior season mean benchmarks (ie, 2019-2020 season values minus benchmark values). Unexplained deaths were defined as all-cause deaths either not reported in any diagnostic category (unreported) or reported in the NEC category (unspecified). Explained deaths were defined as all-cause deaths reported in any of the specific cause-of-death categories (ie, all-cause minus unexplained deaths). Changes in explained and unexplained causes were calculated using the same method as for excess deaths, by first calculating the populationadjusted prior season mean benchmarks, then subtracting the benchmark values from the 2019-2020 season values.

\section{RESULTS}

Of a total of 16.3 million all-cause deaths reported over six influenza seasons in 48 states, 2.98 million occurred during 2019-2020, representing a population-adjusted increase of 288467-319858 excess deaths over prior season averages for 2, 3 and 5 years (figure 1, top). Mean annual population-adjusted total all-cause death counts varied modestly across seasonal benchmarks, ranging from 2659228 to 2690619. An increase in NEC deaths began in approximately week 19 and escalated sharply beginning at week 36 (31 May in the 2019-2020 season) through end of observation. Increases in explained and unexplained deaths, respectively, began in approximately week 25 (15 March-21 March in 2020) and week 20 (9 February-15 February in 2020; figure 1, bottom).

Contribution of unexplained mortality to excess deaths varied considerably by pandemic period (table 1; online supplemental appendix 2). Using the 5-year benchmark, of the total increase of 306267 all-cause deaths reported from pandemic awareness through end of observation (seasonal weeks 17-52, 19 January through 26 September 2020), $179903(58.7 \%)$ were attributed to COVID-19; $49311(16.1 \%)$ to changes in reported causes other than COVID-19; 6909 (2.3\%) to increased NEC deaths and $70145(22.9 \%)$ to increases in deaths with no reported cause. On a proportional basis, mortality change with unexplained (unreported or NEC) cause was much greater in the pandemic awareness period (19 January through 28 March, $65.2 \%$ of change in all-cause deaths) than in the initial pandemic peak period (29 March through 30 May, 16.1\%) or the post-peak period (31 May through 26 September, 29.3\%). In total, an increase of 77054 unexplained deaths was responsible for $25.2 \%$ of change in all-cause mortality from 19 January through 26 September 2020.

Results using the 2-year and 3-year benchmarks were similar (online supplemental appendix 3). Using these benchmarks, increases in unexplained deaths accounted for $68.0 \%-72.5 \%$ of excess deaths during the pandemic awareness period; $14.1 \%-14.5 \%$ of excess deaths during initial peak and $26.6 \%-27.4 \%$ of excess deaths in the pandemic post-peak period. Measured from pandemic awareness through the end of observation, changes in unexplained deaths accounted for $22.2 \%-22.9 \%$ of excess deaths.

\section{DISCUSSION}

This analysis of population-adjusted US death certificate data for six influenza seasons, the first to assess the extent and timing of unexplained pandemic deaths, indicated 

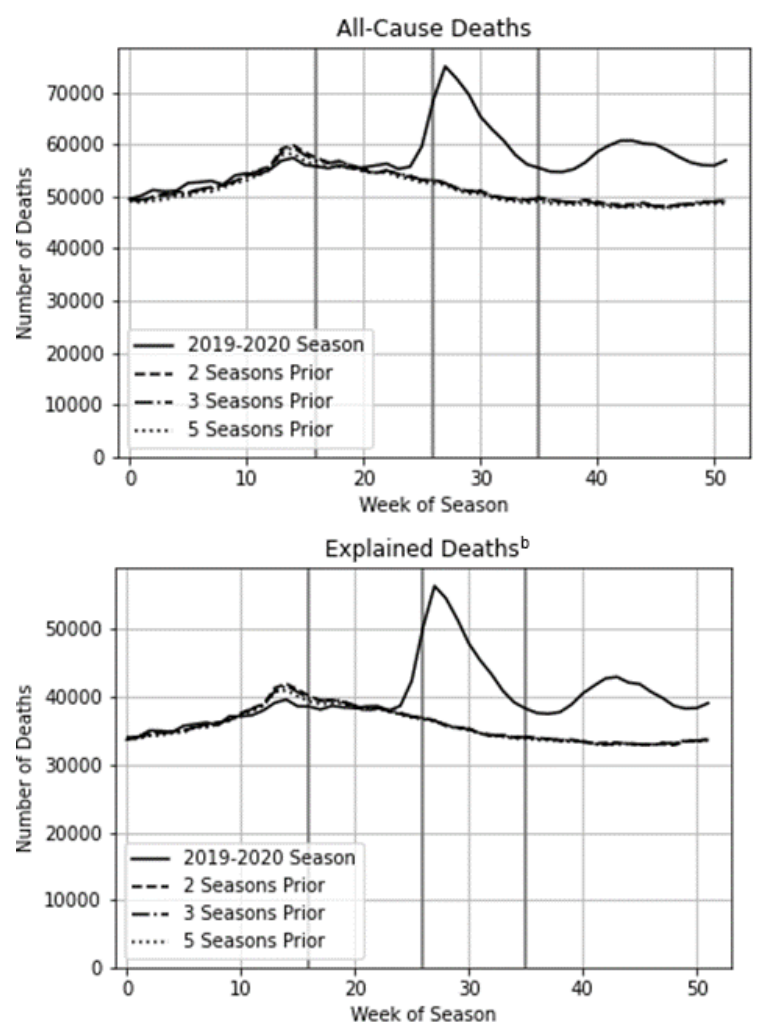

Not Elsewhere Classified Deaths
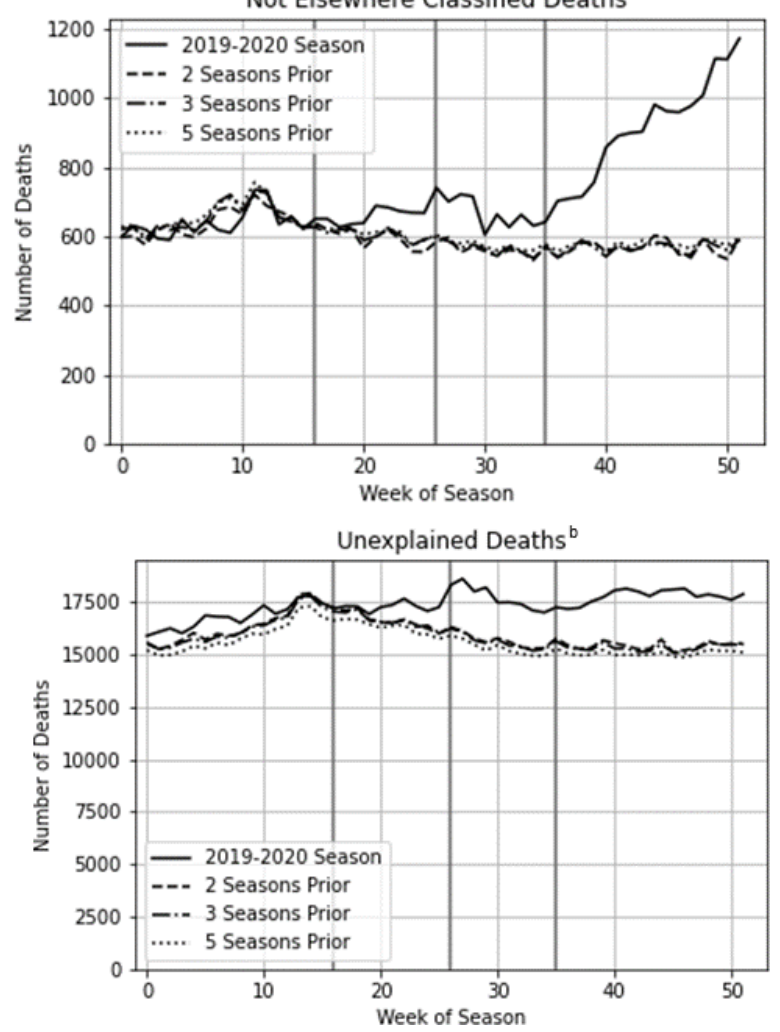

Figure 1 Trends in population-adjusted death counts by week of influenza season, ${ }^{\text {a }} 2014-2015$ through $2019-2020$ seasons. ${ }^{a}$ For each influenza season, week 1 begins on approximately 1 October and week 52 ends on approximately 30 September. A total of 312 weeks (52 weeks for six seasons) were included in the analyses. Dividing lines represent the ends of weeks 16 (week prior to pandemic awareness period), 26 (week prior to initial pandemic peak) and 35 (week prior to pandemic post-peak period). Prior season benchmarks are means (deaths summed across seasons, divided by 2, 3 and 5, respectively, for twoseason, three-season and five-season benchmarks). Benchmarks for two, three and five seasons, respectively, are indicated by long dashed lines, alternating short and long dashed lines, and dotted lines. ${ }^{b}$ Explained deaths include specific causes reported in the mortality files, including heart disease, cancer, chronic lower respiratory disease, cerebrovascular disease, Alzheimer's disease, diabetes, influenza/pneumonia, other respiratory illness, kidney disease, septicaemia and COVID-19. Diagnosis codes for each category are in online supplemental appendix 1. Unexplained deaths are all-cause deaths with no reported underlying cause or with a not elsewhere classified (NEC) cause (all-cause deaths minus explained deaths). NEC deaths are described in ICD-10 nomenclature as 'symptoms, signs, and abnormal clinical and laboratory findings NEC' (ICD-10 range R00-R99), include 'ill-defined and unknown cause of mortality' (R99), a code commonly used pending forensic investigation of injurious death. ${ }^{24} 25$ ICD-10, International Classification of Diseases, 10th Revision.

substantial impact of unexplained deaths on excess pandemic period mortality. The most important study limitation is that observation ended on 26 September 2020. Results may not apply to subsequent disease activity, including the surge late in $2020,{ }^{29}$ or to other countries. Additionally, this analysis was descriptive, although it produced results for all-cause deaths similar to those using more sophisticated statistical methods. ${ }^{8}$ For example, the 299028 excess deaths estimated by the US Centers for Disease Control and Prevention using Poisson regression modelling through 3 October $2020^{9}$ is comparable with our estimate of 287957-306267 excess deaths through 26 September 2020.

Despite these limitations, the finding that a large proportion of 2020 excess mortality was unexplained by changes in top causes of natural death or respiratory disease suggests a need to extend thinking about pandemic mortality beyond COVID-19 or its physical sequelae. Although drug overdoses and suicides are not reported in the available NCHS data, several factors implicate these as potential causes of the unexplained US deaths. These include reports of increases in rates of serious psychological distress from $3.9 \%$ of adults in 2018 to $13.6 \%$ in April $2020^{20}$ and of an $18.2 \%$ increase in 12-month overdose death rates from June 2019 to May $2020 .^{34}$ The increase in NEC deaths, which accelerated sharply beginning in approximately May 2020, is also consistent with this explanation because the R99 category included in the ICD-10 NEC group is commonly used pending forensic investigation of injurious death, introducing a lag period before cause-of-death determination. ${ }^{24}$ However, the NEC increases could also represent COVID-19 not yet diagnosed because of pending laboratory testing.

Countering suicides but supporting overdose as causal factors underlying the unexplained deaths, US mortality 
Table 1 Overview of changes in reported deaths during pandemic periods, 2019-2020 vs prior five-season benchmark

\begin{tabular}{|c|c|c|c|c|c|c|c|}
\hline & \multirow{2}{*}{$\begin{array}{l}\text { Total } \\
\\
\text { All causes }\end{array}$} & \multicolumn{3}{|l|}{ Explained } & \multicolumn{3}{|c|}{ Unexplained } \\
\hline & & $\begin{array}{l}\text { Reported } \\
\text { UCOD, } \\
\text { COVID-19 }\end{array}$ & $\begin{array}{l}\text { Reported } \\
\text { UCOD, not } \\
\text { COVID-19* }\end{array}$ & $\begin{array}{l}\text { Total } \\
\text { explained } †\end{array}$ & $\begin{array}{l}\text { UCOD } \\
\text { was NEC }\end{array}$ & $\begin{array}{l}\text { Unreported: } \\
\text { all-cause death, } \\
\text { no UCOD } ¥\end{array}$ & $\begin{array}{l}\text { Total } \\
\text { unexplained§ }\end{array}$ \\
\hline \multicolumn{8}{|c|}{ Pandemic awareness period } \\
\hline $\begin{array}{l}\text { Prior season mean } \\
\text { benchmark }\end{array}$ & 546260 & 0 & 383245 & 383245 & 6106 & 156909 & 163015 \\
\hline Change $^{\star *}$ & 14476 & 3578 & 1457 & 5035 & 471 & 8970 & 9441 \\
\hline$\%$ of excess deaths†† & 100.0 & 24.7 & 10.1 & 34.8 & 3.3 & 62.0 & 65.2 \\
\hline \multicolumn{8}{|c|}{ Initial pandemic peak period } \\
\hline $\begin{array}{l}\text { Prior season mean } \\
\text { benchmark }\end{array}$ & 453618 & 0 & 315900 & 315900 & 5175 & 132543 & 137718 \\
\hline$\%$ of excess deaths†† & 100.0 & 69.5 & 14.5 & 83.9 & 0.7 & 15.4 & 16.1 \\
\hline \multicolumn{8}{|l|}{ Pandemic post-peak I } \\
\hline $\begin{array}{l}\text { Prior season mean } \\
\text { benchmark }\end{array}$ & 821482 & 0 & 565731 & 565731 & 9793 & 245958 & 255751 \\
\hline 2019-2020 & 978181 & 82482 & 594026 & 676508 & 15345 & 286328 & 301673 \\
\hline Change $^{\star *}$ & 156699 & 82482 & 28295 & 110777 & 5552 & 40370 & 45922 \\
\hline$\%$ of excess deaths $† \dagger$ & 100.0 & 52.6 & 18.1 & 70.7 & 3.5 & 25.8 & 29.3 \\
\hline \multicolumn{8}{|c|}{ Total changes, pandemic awareness through end of observation } \\
\hline $\begin{array}{l}\text { Prior season mean } \\
\text { benchmark }\end{array}$ & 1821360 & 0 & 1264876 & 1264876 & 21074 & 535410 & 556484 \\
\hline
\end{tabular}

*Sum of specific causes other than COVID-19 reported in the mortality files, including heart disease, cancer, chronic lower respiratory disease, cerebrovascular disease, Alzheimer's disease, diabetes, influenza/pneumonia, other respiratory illness, kidney disease and septicaemia. Diagnosis codes for each category are in online supplemental appendix 1.

†Sum of specific causes plus COVID-19.

$\ddagger$ All-cause deaths not reported in any of the categories of death included in the mortality files, including those listed in footnote *, NEC deaths or COVID-19.

§NEC deaths plus unreported deaths. Online supplemental appendix 2 shows total unexplained deaths expressed as a proportion of all deaths.

IPandemic awareness is from weeks 17 to 26 (19 January through 28 March in 2019-2020 season). Initial pandemic peak is from weeks 27 to 35 (29 March through 30 May in 2019-2020 season). Pandemic post-peak is from weeks 36 to 52 (31 May through 26 September in 2019-2020 season).

**2019-2020 values minus mean benchmark values. Summed numbers may vary by 1 from totals shown due to rounding of the populationadjusted counts. Bolded numbers are excess deaths.

††Change from mean benchmark to 2019-2020, expressed as a percentage of total excess all-cause deaths in 2019-2020.

NEC, not elsewhere classified; UCOD, underlying cause of death.

data reported through August 2020 suggested early pandemic period increases in overdoses, homicides and unintentional injuries, but decreases in suicides and motor vehicle accidents, relative to historical experience. ${ }^{35} \mathrm{An}$ important caveat to these early findings is that they represent the USA as a whole, possibly masking outcomes in economically and socially vulnerable populations that were already at increased risk of behavioural healthrelated mortality prior to the pandemic. ${ }^{36-39}$ Among these are young adults, described in a US Substance Abuse and Mental Health Services Administration (SAMHSA) report as 'a uniquely vulnerable population' based on pandemic period data on anxiety, depression, traumatic stress, psychological distress, loneliness, substance misuse and suicidal ideation. ${ }^{37}$ Also at elevated risk were women, racial and ethnic minorities, healthcare workers and paediatric populations. ${ }^{36-39}$ These disparate behavioural health effects suggest that the underlying causes of excess deaths should be explored in US population subgroups, rather than only for the nation as a whole. 
Also supporting the interpretation of possible behavioural health effects, the timing of onset of unexplained deaths in February 2020 suggests they did not result from COVID-19 or sequelae of COVID-19 deaths (eg, bereavement). Increases in unexplained deaths began about 4-6 weeks before $>1000$ COVID-19 cases had been reported nationwide, ${ }^{29}$ approximately coinciding with extensive media coverage of COVID- $19^{40}$ and a nationwide increase in use of psychotropic medications for anxiety, depression and sleep disorders. ${ }^{41}$ Also supporting this interpretation are survey data from early in the pandemic, suggesting no significant association between psychological distress and personal acquaintance with someone who died of COVID-1 $19^{42}$ but strong associations with fear of COVID-19 contagion and of disruption to finances and employment. ${ }^{18} 20$

Moreover, a content analysis of media coverage of the pandemic, posted as a non-peer-reviewed working paper in November 2020, found that $91 \%$ of US major media stories, compared with $54 \%$ of non-US stories and $65 \%$ of scientific journal reports, were 'negative in tone'. ${ }^{43}$ These preliminary findings suggest a possible bias unique to US media coverage of COVID-19. If confirmed with peer-reviewed research, the connection between this bias and psychological distress should be explored in additional studies. Neither the psychological effects of media coverage nor the specific causes of the unexplained deaths we observed could be assessed with available provisional mortality data. However, release of the full, final US cause-of-death file for 2020, which likely will occur by early 2022, will make analyses of psychiatric and injurious causes of death, overall and by demographic and regional subgroups, feasible.

Expanding pandemic period mortality research to include societal causes would help to evaluate a concern expressed by the SAMHSA about public health harms caused by focus 'solely [on] virus containment' rather than on 'all aspects of health'. ${ }^{44}$ The addition of new UCOD categories for behavioural disorders, including psychiatric and substance use disorders, intentional selfharm and unintentional overdose, to the available files would facilitate this investigation. Together, these causes accounted for approximately 106000 US deaths per year from 2010 to $2018,{ }^{45}$ and their prevalence as UCODs has increased rapidly over time. ${ }^{46}{ }^{47}$ The provisional files released by the NCHS in March of 2021, which included the diagnostic categories assessed in this research plus categories for accidents, intentional self-harm, homicide and drug overdoses, ${ }^{48}$ were aggregated monthly for the USA as a whole and therefore do not facilitate comparative policy analysis, such as by states with varying pandemic policies (eg, strict stay-at-home orders vs precautionary warnings).

Findings also suggest challenges in interpreting excess death reports because of between-group differences in predispositions to various causes of death. ${ }^{17}{ }^{42}$ For example, the largest percentage increase in US pandemic period all-cause deaths occurred in adults aged 25-44 years, ${ }^{9}$ a group with low rates of COVID-19 mortality but elevated rates of anxiety and mood disorders ${ }^{42}$ suggesting possible underlying psychiatric causes. Similarly, the USA had the fourth highest rate of alcohol dependence (8\%) and the highest rate of opioid-related deaths (131 per million) in the world in 2016, ${ }^{17}$ implicating substancerelated mortality as a likely contributor to unexplained deaths. In contrast, in groups with higher rates of risk factors for COVID-19 mortality, such as obesity or smoking, ${ }^{4}$ undetected COVID-19 may be a more likely cause of unexplained all-cause deaths. For example, rates of adult (aged $\geq 15$ years) smoking in 2017 ranged from $11 \%$ or less in the USA and other countries (eg, Mexico, $8 \%$ ) to $\geq 25 \%$ in France, Hungary, Turkey, Greece, Russia and Indonesia. ${ }^{17}$ Similarly, within the USA, statewide rates of obesity among adults in 2020 ranged from $24 \%$ to $40 \%{ }^{49}$

These large risk factor variations across groups and regions could represent markedly disparate true underlying causes for unexplained all-cause deaths. If so, the excess death calculation is uninterpretable when a large proportion of excess deaths is unexplained. This problem, which affected $22 \%-25 \%$ of the excess pandemic period deaths measured through September 2020, suggests that excess death calculations do not consistently provide actionable information and highlights previous calls for specific, standardised algorithms to certify mortality from respiratory illness and other causes on death certificates. ${ }^{13}$

\section{CONCLUSION}

Approximately $22 \%-25 \%$ of excess all-cause mortality during the US 2020 COVID-19 pandemic was unexplained by changes in the top eight causes of natural death, COVID-19, sepsis or other respiratory illness. The onset of unexplained deaths coincided with media coverage and previously reported nationwide increases in psychotropic use. Because unexplained excess deaths may represent disparate underlying causes in different demographic groups or regions, standard excess death calculations may lack utility for evidence-based policymaking. Findings highlight the need for improvements in death certification accuracy.

Contributors KAF and KJG performed concept and design, assisted by JDR and RSZ. Analyses were performed by KAF and JDR, assisted by RSZ. The manuscript was drafted by KAF and revised for important content by all authors. All authors read and approved of the final manuscript. All authors agree to be accountable for all aspects of the work in ensuring that questions related to the accuracy or integrity of any part of the work are appropriately investigated and resolved. As manuscript guarantor, KAF accepts full responsibility for the finished work and the conduct of the study, had access to the data, and controlled the decision to publish.

Funding This manuscript was supported solely by Midwestern University and Kathleen Fairman LTD. The research received no specific grant from any funding agency in the public, commercial, or not-for-profit sectors.

Competing interests KAF is President and JDR is Research Intern with Kathleen Fairman LTD, a for-profit research consulting firm. Kathleen Fairman LTD provided analytical support and article processing charges but has no financial or non- 
financial interests related to the topic of the manuscript. KJG and RSZ have no competing interests to report.

Patient consent for publication Not required.

Provenance and peer review Not commissioned; externally peer reviewed.

Data availability statement Data are available upon reasonable request. Data are available in a public, open access repository.

Supplemental material This content has been supplied by the author(s). It has not been vetted by BMJ Publishing Group Limited (BMJ) and may not have been peer-reviewed. Any opinions or recommendations discussed are solely those of the author(s) and are not endorsed by BMJ. BMJ disclaims all liability and responsibility arising from any reliance placed on the content. Where the content includes any translated material, BMJ does not warrant the accuracy and reliability of the translations (including but not limited to local regulations, clinical guidelines, terminology, drug names and drug dosages), and is not responsible for any error and/or omissions arising from translation and adaptation or otherwise.

Open access This is an open access article distributed in accordance with the Creative Commons Attribution Non Commercial (CC BY-NC 4.0) license, which permits others to distribute, remix, adapt, build upon this work non-commercially, and license their derivative works on different terms, provided the original work is properly cited, appropriate credit is given, any changes made indicated, and the use is non-commercial. See: http://creativecommons.org/licenses/by-nc/4.0/.

\section{ORCID iDs}

Kathleen A Fairman http://orcid.org/0000-0001-8704-7271

Kellie J Goodlet http://orcid.org/0000-0002-9736-0891

\section{REFERENCES}

1 Rampatige R, Mikkelsen L, Hernandez B, et al. Systematic review of statistics on causes of deaths in hospitals: strengthening the evidence for policy-makers. Bull World Health Organ 2014;92:807-16.

2 Brown TS, Dubowski K, Plitt M, et al. Erroneous reporting of deaths attributed to pneumonia and influenza at 2 New York City teaching hospitals, 2013-2014. Public Health Rep 2020;135:796-804.

3 Singh B. International comparisons of COVID-19 deaths in the presence of comorbidities require uniform mortality coding guidelines. Int J Epidemiol 2021;50:373-7.

4 U.S. Centers for Disease Control and Prevention. People at increased risk for severe illness: older adults, people with medical conditions, 2021. Available: https://www.cdc.gov/coronavirus/2019-ncov/needextra-precautions/index.html

5 Juyal D, Kumar A, Pal S, et al. Medical certification of cause of death during COVID-19 pandemic - a challenging scenario. J Family Med Prim Care 2020;9:5896-8.

6 West A, Czypionka T, Steffen M, et al. Reporting COVID-19 deaths in Austria, France, Germany, Italy, Portugal and the UK. Working paper 10-20. LSE Department of Social Policy 2020 https://www.Ise.ac.uk/ social-policy/Assets/Documents/PDF/working-paper-series/10-20Anne-West.pdf

7 Bilinski A, Emanuel EJ. COVID-19 and excess all-cause mortality in the US and 18 comparison countries. JAMA 2020;324:2100-2.

8 Weinberger DM, Chen J, Cohen T, et al. Estimation of excess deaths associated with the COVID-19 pandemic in the United States, March to May 2020. JAMA Intern Med 2020;180:1336-44.

9 Rossen LM, Branum AM, Ahmad FB, et al. Excess deaths associated with COVID-19, by age and race and ethnicity-United States, January 26-October 3, 2020. MMWR Morb Mortal Wkly Rep 2020;69:1522-7.

10 Davies B, Parkes BL, Bennett J, et al. Community factors and excess mortality in first wave of the COVID-19 pandemic in England. Nat Commun 2021;12:3755.

11 Rucker J. Unexplained pandemic mortality. technologies. Available: https://github.com/JamesRucker/Unexplained_deaths

12 U.S. Centers for Disease Control and Prevention, National Center for Health Statistics. Public use data file documentation, mortality multiple cause-of-death. Available: https://www.cdc.gov/nchs/nvss/ mortality_public_use_data.htm

13 U.S. Centers for Disease Control and Prevention, National Center for Health Statistics. Weekly provisional counts of deaths by state and select causes, 2020-2021. Available: https://data.cdc.gov/NCHS/ Weekly-Counts-of-Deaths-by-State-and-Select-Causes/muzy-jte6

14 U.S. Centers for Disease Control and Prevention, National Center for Health Statistics. Weekly counts of deaths by state and select causes, 2014-2019. Available: https://data.cdc.gov/NCHS/WeeklyCounts-of-Deaths-by-State-and-Select-Causes/3yf8-kanr

15 Doucette ML, Tucker A, Auguste ME, et al. Initial impact of COVID-19's stay-at-home order on motor vehicle traffic and crash patterns in Connecticut: an interrupted time series analysis. Inj Prev 2021;27:3-9.

16 Kansagra AP, Goyal MS, Hamilton S, et al. Collateral effect of Covid-19 on stroke evaluation in the United States. N Engl J Med 2020;383:400-1.

17 Organisation for Economic Co-operation and Development. Health at a Glance 2019: OECD Indicators, OECD Publishing, Paris. Indicators, OECD Publishing, Paris.

18 Novotný JS, Gonzalez-Rivas JP, Kunzová Šárka, et al. Risk factors underlying COVID-19 lockdown-induced mental distress. Front Psychiatry 2020;11:60314.

19 Niedzwiedz CL, Green MJ, Benzeval M, et al. Mental health and health behaviours before and during the initial phase of the COVID-19 lockdown: longitudinal analyses of the UK household longitudinal study. J Epidemiol Community Health 2021;75:224-31.

20 McGinty EE, Presskreischer R, Anderson KE, et al. Psychological distress and COVID-19-related stressors reported in a longitudinal cohort of US adults in April and July 2020. JAMA 2020;324:2555-7.

21 Fairman KA, Goodlet KJ, Rucker JD. Changes in cause-of-death attribution during the Covid-19 pandemic: association with hospital quality metrics and implications for future research. MedRxiv 2020 https://www.medrxiv.org/content/

22 Miniño A. Coding and classification of causes of death in accordance with the tenth revision of the international classification of diseases. National Center for Health Statistics. Available: https://www.cdc.gov/ nchs/ppt/nchs2012/li-14_minino.pdf

23 Heron M. Deaths: leading causes for 2017. Natl Vital Stat Rep 2019;68:1-77 https://www.cdc.gov/nchs/data/nvsr/nvsr68/nvsr68_ 06-508.pdf

24 Spencer MR, Ahmad F. Timeliness of death certificate data for mortality surveillance and provisional estimates. Vital statistics rapid release, 2016. Available: https://www.cdc.gov/nchs/data/vsrr/ report001.pdf

25 International classification of diseases, 10th revision. Available: https://www.icd10data.com

26 Pérez F, Granger BE, Hunter JD. Python: an ecosystem for scientific computing. Comput Sci Eng 2011;13:13-21.

27 McKinney W. Data structures for statistical computing in python. Proceedings of the 9th Python in Science Conference 2010;445:56-61.

28 U.S. Census Bureau. State population totals and components of change: 2010-2019. U.S. census bureau. table 1. Available: https:// www.census.gov/data/tables/time-series/demo/popest/2010s-statetotal.html

29 U.S. Centers for Disease Control and Prevention. CDC COVID data tracker: trends in number of COVID-19 cases and deaths in the US reported to CDC, by state/territory, United States. Available: https:// covid.cdc.gov/covid-data-tracker/\#trends dailytrendscases

30 Miller JE. The Chicago guide to writing about multivariate analysis. Chicago, IL: University of Chicago Press, 2005.

31 Ahmad FB, Anderson RN. The leading causes of death in the US for 2020. JAMA 2021;325:1829-30.

32 Vandenbroucke JP, von Elm E, Altman DG, et al. Strengthening the reporting of observational studies in epidemiology (STROBE) explanation and elaboration. Ann Intern Med 2007;147:W-94.

33 Hunter JD. Matplotlib: a 2D graphics environment. Comput Sci Eng 2007:9:90-5.

34 U.S. Centers for Disease Control and Prevention, Health Alert Network. Increase in fatal drug overdoses across the United States driven by synthetic opioids before and during the COVID-19 pandemic. December 17, 2020. Available: https://emergency.cdc. gov/han/2020/han00438.asp

35 Faust JS, Du C, Mayes KD, et al. Mortality from drug overdoses, homicides, unintentional injuries, motor vehicle crashes, and suicides during the pandemic, March-August 2020. JAMA 2021;326:84-6.

36 Kline D, Pan Y, Hepler SA. Spatiotemporal trends in opioid overdose deaths by race for counties in Ohio. Epidemiology 2021;32:295-302.

37 Substance Abuse and Mental Health Services Administration, Disaster Technical Assistance Center. A preliminary look at the mental health and substance use-related effects of the COVID-19 pandemic, 2021. Available: https://www.samhsa.gov/sites/default/ files/dtac/mental-health-substance-use-effects-covid-pandemicsrb.pdf?utm_source=SAMHSA\&utm_campaign $=557216 \mathrm{f26a}-$ SUPPLEMENTAL BULLETIN 2021 $06 \quad 04$ 1600070\&utm medium $=$ email\&utm_term $=0$ _ee1c4b138c-557216f26a-167840245

38 Yasguar BW. Child suicides drive Colorado hospital to declare state of emergency. Medscape Medical News, 2021. Available: 
https://www.medscape.com/viewarticle/952464\#: :text=On\% 20May\%2025\%2C\%20Jena\%20Hausmann,which\%20has\% 20overwhelmed\%20the\%20institution

39 Chatterjee R. Child psychiatrists warn that the pandemic may be driving up kids' suicide risk, 2021. Available: https://www.npr.org/ sections/health-shots/2021/02/02/962060105/child-psychiatristswarn-that-the-pandemic-may-be-driving-up-kids-suicide-risk

40 Ducharme J. News coverage of coronavirus in 2020 is very different than it was for Ebola in 2018, 2020. Available: https://time.com/ 5779872/coronavirus-ebola-news-coverage/

41 Express Scripts. America's state of mind report, 2020. Available: https://www.express-scripts.com/corporate/americas-state-of-mindreport

42 Czeisler Mark É, Lane RI, Petrosky E, et al. Mental health, substance use, and suicidal ideation during the COVID-19 pandemicUnited States, June 24-30, 2020. MMWR Morb Mortal Wkly Rep 2020;69:1049-57.

43 Sacerdote B, Schgal R, Cook M. Why is all COVID-19 news bad news?. Working paper 28110. Cambridge, MA: National Bureau of Economic Research, 2020. https://www.nber.org/system/files/ working_papers/w28110/w28110.pdf
44 U.S. Department of Health \& Human Services, Substance Abuse and Mental Health Services Administration. SAMHSA statement regarding CDC's MMWR on mental health, substance use, and suicidal ideation during the COVID-19 pandemic. August 14, 2020. Available: https://www.samhsa.gov/newsroom/pressannouncements/202008140930

45 Bohnert ASB, Sen S. Deaths attributed to psychiatric disorders in the United States, 2010-2018. Am J Public Health 2020;110:1825-7.

46 Brignone E, George DR, Sinoway L, et al. Trends in the diagnosis of diseases of despair in the United States, 2009-2018: a retrospective cohort study. BMJ Open 2020;10:e037679.

47 Shanahan L, Copeland WE. Psychiatry and deaths of despair. JAMA Psychiatry 2021;78:695-6.

48 U.S. Centers for Disease Control and Prevention, National Center for Health Statistics. Monthly provisional counts of deaths by select causes, 2020-2021. Available: https://data.cdc.gov/NCHS/ Monthly-Provisional-Counts-of-Deaths-by-Select-Cau/9dzk-mvmi/ data

49 U.S. Centers for Disease Control and Prevention. Adult obesity prevalence maps, 2021. Available: https://www.cdc.gov/obesity/ data/prevalence-maps.html 